\title{
US doctors migrating north
}

$\mathrm{W}$

ith the prospect of greater pay, fewer bureaucratic headaches and the opportunity to provide better care for patients, the number of American doctors migrating north is rising, according to Canadian recruiters and Canadian Medical Association data.

Susan Craig, president of the Torontobased physician recruiter, Susan Craig Associates, said that Canada is becoming "increasingly attractive," while John Philpott, the Halifax-based chief executive director of CanAm Physician Recruiting, noted "interest is doubling each year for American doctors" seeking to move north.

Increased pay is the main driver of this interest. Philpott said family physicians, pediatricians and psychiatrists can make \$100 000 more annually in Canada, on average, compared to the US.

According to data from the Canadian Medical Association, the number of UStrained physicians working in Canada grew less than 3\% from 1996 to 2005 (up from 493 to 506), but jumped $42 \%$ from 2006 to 2014 (508 to 721).

The increase would be much higher, however, if estimates distinguished between specialists and family doctors, as the majority of US physicians crossing the border are in family medicine, said Philpott.

In the US, thanks to insurancecompany loopholes and technicalities, American family physicians aren't paid up to $30 \%$ of the time, whereas under a single-payer system, only about $2 \%$ of his billings aren't covered, explained Dr. Sajad Zalzala, a US-trained family physician who moved to Windsor, Ont. in 2012.

Communicating with insurance companies and filing claims is so bewilderingly bureaucratic, in fact, that while "a family physician in Canada can manage with one or two secretaries, in the US, one doctor could need 10 secretaries," said recruiter Susan Craig.

Even referrals are a headache since insurance companies often pay only for

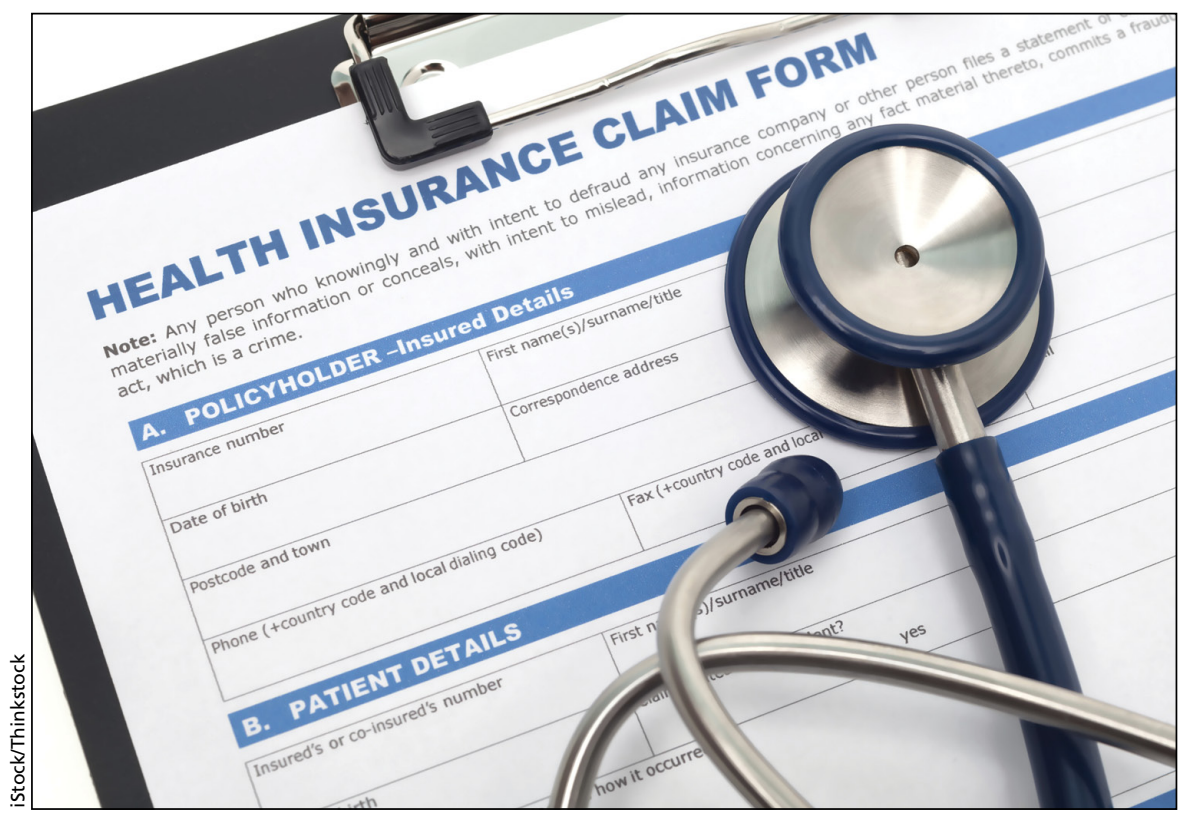

American family physicians can lose out on up to $30 \%$ of earnings due to insurance company loopholes and technicalities.

specific hospitals and specialists, added Zalzala.

The introduction of Obamacare isn't stemming the tide of US physicians heading North. Quite the opposite, in fact.

"For every problem that Obamacare solves, it creates two to three other problems," said Zalzala. For example, the Blue Cross plan under the Affordable Care Act is different from the Blue Cross employer-paid plan, so doctors will have double the paperwork.

\section{Canadian registration constraints}

Depending on the regulations of the provincial colleges of physicians and surgeons, US doctors must either undergo a period of supervision (usually several months to a year) or complete the Medical Council of Canada exams, or both, to obtain a full license to practise in Canada.

There are numerous procedural delays, and doctors are often required to show that they have a job before they are allowed to start the process. This can lead to a period of unemployment, said Dr. Bridget Reidy, who moved north two years ago and has worked as a locum doctor in Prince Edward Island, as a fulltime physician in Ontario and is about to start a job in BC.

"I think a lot more doctors would want to work in Canada if [the licensing process] was easier," she said, adding that the barriers are a shame since most provinces "desperately need doctors."

Since the credentials of US-trained doctors are recognized by the College of Family Physicians of Canada (CFPC), Philpott doesn't understand why the provincial colleges put barriers up.

"The provincial colleges are slapping the CFPC in the face," said Philpott. "I guess they feel they have a greater understanding of certification than our own national bodies."

But Craig thinks the supervision is a "wise thing." There are billing practices and different drug names to be learned, and American doctors often feel the need to order more tests - a practice known as defensive medicine - to avoid lawsuits, she said. "In the US, they practise fairly intensive defensive medicine, and in Canada we don't encourage that."

Another attraction for US family 
doctors is that their work is more valued in Canada, said Reidy, who explained that US patients tend to go to walk-in clinics or straight to specialists. "There's just not that understanding of the need for someone to be the captain of the outpatient care. Doing proper care becomes more difficult as a result," she said.
Dr. John Lucas, who practises psychiatry in both Goshen, New York, and Owen Sound, Ont., said he appreciates that his Canadian patients can access psychiatric services much more easily than in the US, and are supported through social programs rather than being "criminalized" like they are south of the border.
And Zalzala appreciates the lack of a "defensive medicine" culture. "If I'm worried about missing something, it's because I'll feel terrible for the patient, not because the patient will come back and sue me," he said. - Wendy Glauser, Toronto, Ont.

CMAJ 2014. DOI:10.1503/cmaj.109-4805 